\title{
Flashbulb memories of the Charlie Hebdo attack.
}

\author{
Marie-Charlotte Gandolphe, Mohamad EI Haj \\ Univ Lille, CNRS, CHU Lille, Sciences Affectives, Lille, France.
}

\begin{abstract}
Flashbulb memories refer to the vivid recall of the circumstances of first learning about significant public events. Our paper assesses whether these memories were triggered by the attack on the satirical French newspaper "Charlie Hebdo". Participants answered a webbased questionnaire that assessed their memory of the circumstances in which they first learned of the attack (i.e., the reception context). The results showed substantial and vivid recall of the reception context. This recall was also associated with fair rehearsal, negative emotional valence, a wide variety of emotional feelings, surprise, novelty, consequentiality and importance. Furthermore, the flashbulb recall was predicted by the international importance of the attack and the number of people with whom discussions were held about it. The international importance seems to play an important role in the formation of flashbulb memories, at least for the Charlie Hebdo attack, due to the international condemnation and solidarity with the victims.
\end{abstract}

Keywords: Autobiographical memory; Charlie hebdo attack; Flashbulb memory

Accepted August 24, 2016

\section{Introduction}

On 7 January 2015, two gunmen opened fire in the Paris headquarters of the satirical newspaper "Charlie Hebdo", killing twelve individuals, including two police officers. In the wake of the shooting, a day of national mourning was declared and a series of rallies took place in cities across France. Terror alert was raised to its highest level and soldiers were deployed in Paris. Considering these social and political consequences, our paper assessed the psychological consequences of the Charlie Hebdo attack, namely, whether this event has triggered flashbulb memories.

Flashbulb memories are detailed, vivid and long-lasting autobiographical memories of attributes of the reception context of surprising and emotionally arousing public events. According to Brown and Kulik, people may retain for a long time the circumstances in which they first learned of the events, such as where they were when the event occurred, their ongoing activities, and who informed them about the event [1]. The authors first tested their assumption by asking participants to provide details about the context in which they first learned of surprising public events, such as the assassination of John F Kennedy. They found high recall of the reception context and further related these flashbulb memories with several factors, such as novelty, surprise and the personal consequentiality of these events.
Since the original work of Brown and Kulik, flashbulb memories have been observed for a wide range of emotional and surprising public events [1], such as the fall of the Berlin Wall in 1989 [2], the resignation of the British prime minister Margaret Thatcher in 1990 [3], the beginning of operation Desert Storm in 1991 [4], the death of the Belgian king Baudouin in 1993 [5], the death of French president François Mitterrand in 1996 [6], the death of Princess Diana in 1997 [7], the attacks of September 112001 in the United States [8-14], the death of pope John Paul II in 2005 [15], and the resignation of Pope Benedict XVI [16]. Although these studies addressed different events across cultures and countries, most of them emphasized the core element of flashbulb memories, that is, the significant recall of the context in which participants first learned about these events, even one year after they had occurred.

The formation of flashbulb memories can be attributed to several factors, such as novelty, surprise, importance, rehearsal, prior knowledge, and opinion. Concerning novelty and surprise, Brown and Kulik argued that public events must be new and unexpected to initiate surprise and, consequently, to form flashbulb memories [1]. Concerning importance, Tinti et al. compared flashbulb memories of the death of Pope John Paul II in Italian, Polish, and Swiss Catholic participants. The authors found the Polish 
participants had the most flashbulb memories, which was attributed to the great importance of the Pope to them, given that the Pope was Polish and had been involved with the Polish resistance movement during the fall of the Soviet Union. The assumption of Tinti et al. was further tested with structural equation modeling, suggesting that importance, both at the personal and societal level, influences the emotional experience of flashbulb memories [15]. Concerning rehearsal, this mechanism has often been shown to be an important factor in the maintenance of flashbulb memories [1]. The rehearsal of these memories can take place during conversations and/or when people think about the events. Besides rumination, rehearsal can occur during media reports after the events (e.g. TV, radio, newspapers, and internet). It can improve flashbulb memories by reinforcing existing memory; it can also modify the content of these memories since, when talking about the events, people may gradually construct a story that addresses the communicative demands and the interpersonal situation rather than the accuracy of their recall [5]. Prior knowledge and opinion related to the event are also of central importance in flashbulb memory formation since they may facilitate the organization and assimilation of the reception context into existing structures in the memory [3].

Thus, the formation of flashbulb memories can be attributed to novelty, surprise, consequentiality, importance, rehearsal, prior knowledge, and opinion. Emotion is also thought to play a central role. According to Finkenauer et al. once received, the original event is appraised in terms of novelty and importance; the appraisal of novelty leads to a reaction of surprise while the appraisal of importance, together with the level of surprise, defines the level of the emotional feeling state. As well as being highlighted by the model of Finkenauer et al. the emotional contribution has been widely emphasized by research on flashbulb memories [5]. As previously mentioned, these memories were defined as being related to emotionally arousing public events [1]. In a similar vein, flashbulb memories were found to imply greater emotional involvement than everyday life events [17].

In our view, the appraisal of novelty of the unexpected public event can be followed by an appraisal of importance and consequentiality which, in turn, leads to emotional feeling states such as sadness, fear or anxiety [18]. Another predictor of flashbulb memories is rehearsal, which may occur during ruminations, communication with other people and/or while following the media $[1,5,15,18]$. Prior knowledge and opinion related to the event are also of central importance in flashbulb memory formation since they may facilitate the organization and assimilation of the reception context into existing structures in the memory [3].

To summarize, flashbulb memories refer to the vivid recall of attributes of the reception context of surprising and emotionally arousing public events. Our paper assesses whether these memories were triggered by the Charlie Hebdo attack. With this aim, participants answered an online survey about their memory of the event and its reception context; they also answered questions assessing the vividness of the recall. Predictors of flashbulb memory were assessed with questions about the rehearsal, emotion, surprise, novelty, consequentiality and importance of the event. Prior knowledge and opinion were also evaluated. Due to the exploratory nature of this study, no specific hypothesis was made about which factor would significantly predict flashbulb memory.

\section{Method}

\section{Participants}

The study included 235 participants of French nationality and living in France (169 women and 66 men, $M$ age $=31.81$ years, $S D=15.47)$. Participants were recruited through social networking (e.g. the Facebook page of the University of Lille, Facebook pages dedicated to online surveys, etc.) to answer a web-based questionnaire.

\section{Materials}

The web-based questionnaire was administered to the participants via Qualtrics.com. Participation occurred four to five weeks after the shooting.

The survey began by informing the participants about confidentiality, anonymity, and their right to cease their contribution at any time. It also asked participants not to search for answers (for event memory items) on the internet or elsewhere. Afterward, questions on event memory, flashbulb memory, vividness, and predictors of flashbulb memory were provided. All items were based on classic flashbulb memory questionnaires $[1,5,15,18]$.

Event memory was assessed by five items concerning general information about the Charlie Hebdo attack: the date, time, and location of the attack and the number of shooters and victims. For each item, one point was attributed when respondents provided a correct answer and zero when they provided a wrong answer [19]. For instance, responses indicating that the attack occurred on 6 January 2015 (instead of 7 January 2015) were considered wrong. The accurate answer for the time of the attack was 11 AM with a margin of error of $\pm 30 \mathrm{~min}$. Outside this margin, the answers were considered wrong. Vague responses (e.g. "in a building" instead of "the newspaper's headquarters"), "I do not know" responses, and the absence of responses were attributed zero values. It is worth noting that responses were coded by two raters and an inter-rater agreement coefficient of 0.88 and higher was obtained (as assessed by the intra-class correlation coefficient, twoway, random affects model [20].

Flashbulb memory was assessed by ten items concerning the context in which participants first learned of the attack: how they first learned about it, where they were, with whom they were, what they were doing, what they were 
wearing, the day of the week and time of learning, their feelings, reactions, and thoughts. One point was attributed when respondents were able to provide an answer and a score of zero was attributed when they could not; "I do not know" responses were also attributed zero values [5]. An inter-rater agreement of 0.95 and higher was also obtained for answers on flashbulb memory.

Vividness was assessed by four items about visual imagery, auditory imagery, physiological reviviscence, and mental time travel. These items were rated on four-point scale: not at all $=1$, a little $=2$, moderately $=3$, quite a bit $=4$, extremely $=5$ and were based on the Autobiographical Memory Questionnaire [21], which assesses metacognitive judgments of autobiographical reliving.

The remaining items assessed predictors of flashbulb memory, namely, rehearsal, emotion, surprise, novelty, consequentiality, importance, prior knowledge, and opinion. Rehearsal was assessed by five items, assessing following the media, frequency of thoughts, and social sharing. Emotional valence was assessed by one item ranging from "very negative" to "very positive". Emotional state was assessed by one item about 14 different feelings (e.g. sadness, confusion, frustration, etc.). Surprise and novelty were assessed by one item each. Appraisal of consequentiality was assessed by two items on which participants rated the impact of the shooting in the past and present. Appraisal of importance was assessed by four items on which participants rated to what extent the event was important to themselves, families/friends, the country, and the international community. As for prior knowledge, participants rated whether they knew about the existence of the newspaper prior to the shooting, and whether they read the newspaper prior to the shooting. Finally, participants rated their opinion about the newspaper and agreement with its values.

\section{The Survey}

The survey is depicted in Appendix.

\section{Results}

First, the numbers of participants who correctly answered the event memory questions and those who answered the flashbulb memory questions were analyzed. Answers to questions assessing predictors of flashbulb memory, which were rehearsal, emotion, surprise, novelty, consequentiality, importance, prior knowledge and opinion, were also analyzed. Finally, predictors of flashbulb memory were identified by regression analysis.

\section{Large Number of Correct Responses for Event Memory}

Here, the number of participants who provided correct answers for each of the five event memory questions was assessed. As presented in Table 1, one hundred and eighty-eight participants correctly remembered the date of the shooting, whereas 47 participants failed to do so $\left[\chi^{2}(1, N=235)=84.60, p<0.001\right]$. One hundred and forty- one participants correctly remembered the time of the shooting, whereas 94 participants failed to do so $\left[\chi^{2}(1\right.$, $N=235)=9.40, p<0.01]$. Two hundred and twenty-nine participants correctly remembered the location of the shooting, whereas six participants failed to do so $\left[\chi^{2}(1\right.$, $N=235)=211.61, p<0.001]$. Two hundred and sixteen participants correctly remembered the number of shooters, whereas nineteen participants failed to do so $\left[\chi^{2}(1\right.$, $N=235)=165.14, p<0.001]$. No significant differences were observed between participants who correctly remembered the number of victims $(N=110$ participants $)$ and those who failed to do so ( $N=125$ participants) $\left[\chi^{2}(1\right.$, $N=235)=0.96, p>0.1]$.

The number of correct answers to the five event memory questions were then compared with the number of incorrect/“I do not know" responses. Chi square tests showed more of the former than of the latter $\left[\chi^{2}(1\right.$, $N=1175)=299.27, p<0.001]$.

\section{Flashbulb Memory of the Attack}

Two hundred and thirty-four participants described how they first became aware of the shooting, whereas only one participant failed to do so $\left[\chi^{2}(1, N=235)=231.01, p<0.001\right]$. Two hundred and thirty-one participants described where they were when they learned about the shooting, whereas four participants failed to do so $\left[\chi^{2}(1, N=235)=219.27\right.$, $p<0.001]$. Two hundred and twenty-eight participants described who they were with when they learned about the shooting, whereas seven participants failed to do so $\left[\chi^{2}(1\right.$, $N=235)=207.83, p<0.001]$. Two hundred and seventeen participants described what they were doing when they learned about the shooting, whereas eighteen participants failed to do so $\left[\chi^{2}(1, N=235)=168.51, p<0.001\right]$. No significant differences were observed between participants who described what they were wearing when they learned about the shooting $(N=117)$ and those who failed to do so $(N=118)\left[\chi^{2}(1, N=235)=0.44, p>0.1\right]$. Two hundred and twenty-five participants described what day of the week it was when they learned about the shooting, whereas ten participants failed to do so $\left[\chi^{2}(1, N=235)=196.70\right.$, $p<0.001]$. Two hundred and sixteen participants described what time it was when they learned about the shooting, whereas nineteen participants failed to do so $\left[\chi^{2}(1\right.$, $N=235)=165.14, p<0.001]$. Two hundred and twenty-five participants described their feelings when learning about the shooting, whereas ten participants failed to do so $\left[\chi^{2}(1\right.$, $N=235)=196.70, p<0.001]$. Two hundred and eighteen participants described their reactions when learning about the shooting, whereas seventeen participants failed to do so $\left[\chi^{2}(1, N=235)=171.91, p<0.001\right]$. Two hundred and two participants described their thoughts when learning about the shooting, whereas thirty-three participants failed to do so $\left[\chi^{2}(1, N=235)=121.54, p<0.001\right]$.

The number of answers to the ten flashbulb memory questions $(N=2113)$ were then compared with the number of lacking/“I do not know" responses $(N=237)$. Chi square 
Table 1. Number of correct answers in the assessment of event memory and flashbulb memory and ratings of vividness, rehearsal, emotion, surprise, novelty, consequentiality, importance, prior knowledge and opinion

\begin{tabular}{|c|c|c|c|}
\hline Item & Component & Description of variable & Data \\
\hline 1 & \multirow{5}{*}{ Event memory } & \multirow{5}{*}{$\begin{array}{l}\text { Number of provided answers (date) among } 235 \text { subjec } \\
\text { Number of provided answers (time) } / 235 \text { subjects } \\
\text { Number of provided answers (where)/235 subjects } \\
\text { Number of provided answers (shooters) } / 235 \text { subjects } \\
\text { Number of provided answers (victims) } / 235 \text { subjects }\end{array}$} & $N=188$ \\
\hline 2 & & & $N=141$ \\
\hline 3 & & & $N=229$ \\
\hline 4 & & & $N=216$ \\
\hline 5 & & & $N=110$ \\
\hline 6 & \multirow{10}{*}{ Flashbulb memory } & \multirow{10}{*}{$\begin{array}{l}\text { Number of provided answers (how) } / 235 \text { subjects } \\
\text { Number of provided answers (where) } / 235 \text { subjects } \\
\text { Number of provided answers (with whom) } / 235 \text { subjec } \\
\text { Number of provided answers (doing) } / 235 \text { subjects } \\
\text { Number of provided answers (wearing) } / 235 \text { subjects } \\
\text { Number of provided answers (day) } / 235 \text { subjects } \\
\text { Number of provided answers (time) } / 235 \text { subjects } \\
\text { Number of provided answers (feeling) } / 235 \text { subjects } \\
\text { Number of provided answers (reaction) } / 235 \text { subjects } \\
\text { Number of provided answers (thought) } / 235 \text { subjects }\end{array}$} & $N=234$ \\
\hline 7 & & & $N=231$ \\
\hline 8 & & & $N=228$ \\
\hline 9 & & & $N=217$ \\
\hline 10 & & & $N=117$ \\
\hline 11 & & & $N=225$ \\
\hline 12 & & & $N=216$ \\
\hline 13 & & & $N=225$ \\
\hline 14 & & & $N=218$ \\
\hline 15 & & & $N=202$ \\
\hline 16 & \multirow{4}{*}{ Vividness } & \multirow{4}{*}{$\begin{array}{l}\text { Visual imagery (not at all }=1 \text {, extremely }=5 \text { ) } \\
\text { Auditory imagery (not at all }=1 \text {, extremely }=5 \text { ) } \\
\text { Physiological reaction (not at all }=1 \text {, extremely }=5 \text { ) } \\
\text { Travel in time (not at all }=1 \text {, extremely }=5 \text { ) }\end{array}$} & $(M=4.17, S D=1.17)$ \\
\hline 17 & & & $(M=3.11, S D=1.50)$ \\
\hline 18 & & & $(M=3.16, S D=1.59)$ \\
\hline 19 & & & $(M=3.17, S D=1.44)$ \\
\hline 20 & \multirow{5}{*}{ Rehearsal } & \multirow{5}{*}{$\begin{array}{l}\text { Following the media (never }=1 \text {, every day }=5 \text { ) } \\
\text { Rumination (never }=1 \text {, every day }=5 \text { ) } \\
\text { Talking (never }=1 \text {, every day }=5 \text { ) } \\
\text { Talked with (no one }=1 \text {, more than ten people }=5 \text { ) } \\
\text { First talked (in the following weeks }=1 \text {, the same time }=5 \text { ) }\end{array}$} & $(M=4.24, S D=1.02)$ \\
\hline 21 & & & $(M=3.82, S D=0.92)$ \\
\hline 22 & & & $(M=3.57, S D=0.80)$ \\
\hline 23 & & & $(M=4.23, S D=0.82)$ \\
\hline 24 & & & $(M=3.01, S D=1.81)$ \\
\hline 25 & Emotional valence & (very negative $=-2$, very positive $=2$ ) & $(M=-1.44, S D=0.79)$ \\
\hline 26 & \multirow{14}{*}{ Emotional feelings } & (not at all concerned $=-2$, very concerned $=2$ ) & $(M=.99, S D=1.32)$ \\
\hline 27 & & (not at all shocked $=-2$, very shocked $=2$ ) & $(M=1.11, S D=1.21)$ \\
\hline 28 & & (not at all confused $=-2$, very confused $=2$ ) & $(M=0.40, S D=1.49)$ \\
\hline 29 & & (not at all sad=-2, very sad=2) & $(M=1.01, S D=1.11)$ \\
\hline 30 & & (not at all angry $=-2$, very angry $=2$ ) & $(M=0.27, S D=1.79)$ \\
\hline 31 & & (not at all furious $=-2$, very furious $=2$ ) & $(M=0.09, S D=1.31)$ \\
\hline 32 & & (not at all afraid $=-2$, very afraid $=2$ ) & $(M=0.82, S D=1.35)$ \\
\hline 33 & & (not at all anxious $=-2$, very anxious $=2$ ) & $(M=0.34, S D=1.41)$ \\
\hline 34 & & (not at all worried $=-2$, very worried $=2$ ) & $(M=0.87, S D=1.28)$ \\
\hline 35 & & (not at all panicked $=-2$, very panicked $=2$ ) & $(M=-0.06, S D=1.11)$ \\
\hline 36 & & (not at all powerless $=-2$, very powerless $=2$ ) & $(M=0.05, S D=1.58)$ \\
\hline 37 & & (not at all disappointed $=-2$, very disappointed $=2$ ) & $(M=0.87, S D=1.31)$ \\
\hline 38 & & (not at all insecure $=-2$, very insecure $=2$ ) & $(M=0.88, S D=1.39)$ \\
\hline 39 & & (not at all frustrated $=-2$, very frustrated $=2$ ) & $(M=-0.16, S D=1.46)$ \\
\hline 40 & Surprise & (not at all surprised $=-2$, very surprised $=2$ ) & $(M=1.21, S D=1.13)$ \\
\hline 41 & Novelty & (very unusual=-2, very usual=2) & $(M=-0.81, S D=1.28)$ \\
\hline 42 & \multirow{2}{*}{ Consequentiality } & \multirow{2}{*}{$\begin{array}{l}\text { Past impact (no impact at all }=-2 \text {, a lot of impact }=2 \text { ) } \\
\text { Present impact (no impact at all }=-2 \text {, a lot of impact }=2 \text { ) }\end{array}$} & $(M=0.41, S D=0.75)$ \\
\hline 43 & & & $(M=0.23, S D=0.80)$ \\
\hline 44 & \multirow{4}{*}{ Importance } & \multirow{4}{*}{$\begin{array}{l}\text { To the subject (not at all important }=-2 \text {, very important }=2 \text { ) } \\
\text { To family/friends (not at all important=-2, very important=2) } \\
\text { To the country (not at all important=-2, very important=2) } \\
\text { International (not at all important }=-2 \text {, very important }=2 \text { ) }\end{array}$} & $(M=0.70, S D=1.15)$ \\
\hline 45 & & & $(M=0.56, S D=1.02)$ \\
\hline 46 & & & $(M=1.66, S D=.68)$ \\
\hline 47 & & & $(M=1.21, S D=.97)$ \\
\hline 48 & \multirow{2}{*}{ Prior knowledge } & \multirow{2}{*}{$\begin{array}{l}\text { Newspaper existence (not at all }=-2 \text {, absolutely=2) } \\
\text { Past reading (not at all }=-2 \text {, absolutely }=2 \text { ) }\end{array}$} & $(M=1.87, S D=1.31)$ \\
\hline 49 & & & $(M=-0.63, S D=1.11)$ \\
\hline 50 & \multirow{2}{*}{ Opinion } & (very unsympathetic $=-2$, very sympathetic $=2$ ) & $(M=0.85, S D=1.19)$ \\
\hline 51 & & (not at all $=-2$, absolutely $=2$ ) & $(M=0.33, S D=1.23)$ \\
\hline
\end{tabular}


tests showed more of the former than of the latter $\left[\chi^{2}(1\right.$, $N=2350)=1274.43, p<0.001]$.

\section{Fair Vividness of the Reception Context}

The Wilcoxon Signed Rank test was used due to the abnormal distribution of the data. The rating of visual imagery (i.e., "When you remember the moment when you first learned about the shooting, do you see this moment in your mind?") $(M=4.17, S D=1.17)$ was significantly higher than the value of the responses "quite a bit" $(M=4.00$, $S D=0.00) \quad(Z=-2.53, \quad p<0.05)$, but significantly lower than "extremely" responses $(M=5.00, S D=0.00)(Z=-$ $8.97, p<0.001)$. No significant differences were observed between the ratings of auditory imagery (i.e., "When you remember the moment when you first learned about the shooting, do you hear this moment in your mind?") $(M=3.11, S D=1.50)$ and the value of "moderately" responses $(M=3.00, S D=0.00) \quad(Z=-1.18, p>0.1)$. No significant differences were observed between the ratings of physiological reaction (i.e., "When you remember the moment when you first learned about the shooting, do you feel any physiological reaction?") $(M=3.16, S D=1.59)$ and the value of "moderately" responses $(M=3.00$, $S D=0.00) \quad(Z=-1.13, p>0.1)$. No significant differences were observed between the ratings of mental time travel (i.e. "When you remember the moment when you first learned about the shooting, do you feel that you travel back to the time it happened?") $(M=3.17, S D=1.44)$ and the value of "moderately" responses $(M=3.00, S D=0.00)$ $(Z=-1.58, p>0.1)$.

The mean rating of vividness (mean rating of the four vividness items, $M=3.40, S D=0.97$ ) was significantly higher than the value of the responses "moderately" $(M=3.00, S D=0.00)(Z=-5.84, p<0.001)$, but significantly lower than "quite a bit" responses $(M=4.00, S D=0.00)$ $(Z=-7.91, p<0.001)$. Hence, recall of the reception context was associated with fair, but not very high, vividness.

\section{Fair Rehearsal of the Shooting}

Following the media was assessed by the question "Since the announcement of the shooting, how closely have you followed the media coverage?" The rating ( $M=4.24$, $S D=1.02$ ) was significantly higher than the values of "many times a week" $(M=4.00, S D=0.00)(Z=-4.04, p<0.001)$, but significantly lower than "every day" $(M=5.00$, $S D=0.00)(Z=-9.29, p<0.001)$. For the question "Since its announcement, how many times have you thought about the shooting?" the rating $(M=3.82, S D=0.92)$ was significantly higher than the values of "once a week" $(M=3.00, S D=0.00)(Z=-9.98, p<0.001)$, but significantly lower than "many times a week" $(M=4.00, S D=0.00)(Z=-$ $3.20, p<0.001)$. For the question "Since its announcement, how many times have you talked about the shooting?" the rating $(M=3.57, S D=0.80)$ was significantly higher than the values of "once a week" $(M=3.00, S D=0.00)(Z=-$ $8.86, p<0.001)$, but significantly lower than "many times a week" $(M=4.00, S D=0.00)(Z=-7.24, p<0.001)$. For the question "Since its announcement, how many people have you talked to about the shooting?" the rating $(M=4.23$, $S D=0.82$ ) was significantly higher than the values of "six to ten people" $(M=4.00, S D=0.00)(Z=-4.18, p<0.001)$, but significantly lower than "more than ten people" $(M=5.00$, $S D=0.00)(Z=-10.22, p<0.001)$. No significant differences were observed between ratings on the question "When did you first talk about the shooting?" $(M=3.01, S D=1.81)$ and the value of "in the following three days" $(M=3.00$, $S D=0.00)(Z=-0.48, p>0.1)$.

Taken together, these data show that, after the announcement of the shooting, participants followed the media more than many times a week. They also thought and talked about the shooting more than once a week and talked with a fair number of people about the event in the three days following the shooting.

\section{Negative Valence of Emotion}

Emotional valence was rated on the question "Generally speaking, how do you evaluate your emotional reaction when you first learned about the shooting? The mean rating $(M=-1.44, S D=0.79)$ was significantly lower than the value of the answer "negative" $(M=-1.00, S D=0.00)$ $(Z=-7.82, p<0.001)$, but higher than that of "very negative" $(M=-2.00, S D=0.00)(Z=-11.31, p<0.001)$.

For emotional feelings, no significant differences were observed between the rating $(M=0.99, S D=1.32)$ and the value of "quite a bit concerned" $(M=1.00, S D=0.00)(Z=-$ $0.42, p>0.1)$. The rating of shock $(M=1.11, S D=1.21)$ was significantly higher than the values of "quite a bit shocked" $(M=1.00, S D=0.00) \quad(Z=-2.18, p<0.05)$, but significantly lower than "very shocked" $(M=2.00$, $S D=0.00)(Z=-7.14, p<0.001)$. The rating of confusion $(M=0.40, S D=1.49)$ was significantly higher than the values of "moderately confused" $(M=0.00, S D=0.00)$ $(Z=-3.60, p<0.001)$, but significantly lower than "quite a bit confused" $(M=1.00, S D=0.00)(Z=-5.73, p<0.001)$. No significant differences were observed between the rating of sadness $(M=1.01, S D=1.11)$ and the value of "quite a bit sad" $(M=1.00, S D=0.00)(Z=-0.16, p>0.1)$. The rating of anger $(M=0.27, S D=1.79)$ was significantly higher than the values of "moderately angry" $(M=0.00, S D=0.00)$ $(Z=-2.36, p<0.05)$, but significantly lower than "quite a bit angry" $(M=1.00, S D=0.00)(Z=-6.84, p<0.001)$. No significant differences were observed between the rating of furiousness $(M=0.09, S D=1.31)$ and "moderately furious" $(M=0.00, \quad S D=0.00) \quad(Z=-0.86, \quad p>0.1)$. No significant differences were observed between the rating of fear $(M=0.82, S D=1.35)$ and "quite a bit afraid" $(M=1.00, S D=0.00) \quad(Z=-1.17, p>0.1)$. No significant differences were observed between the rating of anxiety $(M=0.34, S D=1.41)$ and "moderately anxious" $(M=0.00$, $S D=0.00)(Z=-0.88, p>0.1)$. No significant differences were observed between the rating of worry $(M=0.87$, $S D=1.28)$ and "quite a bit worried" $(M=1.00, S D=0.00)$ $(Z=-1.01, \quad p>0.1)$. No significant differences were 
observed between the rating of panic $(M=-0.06, S D=1.11)$ and "moderately panicked" $(M=0.00, S D=0.00)(Z=-0.24$, $p>0.1)$. No significant differences were observed between the rating of powerlessness $(M=0.05, S D=1.58)$ and "moderately powerless" $(M=0.00, S D=0.00) \quad(Z=-0.42$, $p>0.1)$. No significant differences were observed between the rating of disappointment $(M=0.87, S D=1.31)$ and "quite a bit disappointed" $(M=1.00, S D=0.00)(Z=-1.19$, $p>0.1)$. No significant differences were observed between the rating of insecurity $(M=0.88, S D=1.39)$ and "quite a bit insecure" $(M=1.00, S D=0.00)(Z=-1.24, p>0.1)$. No significant differences were observed between the rating of frustration $(M=-0.16, S D=1.46)$ and "moderately frustrated" $(M=0.00, S D=0.00)(Z=-1.24, p>0.1)$.

\section{Significant Surprise}

The rating of surprise $(M=1.21, S D=1.13)$ was significantly higher than the values of "quite a bit surprised" $(M=1.00$, $S D=0.00)(Z=-3.27, p=0.001)$, but significantly lower than "very surprised" $(M=2.00, S D=0.00)(Z=-7.77, p<0.001)$.

\section{Fair Novelty}

No significant differences were observed between the rating of novelty $(M=-0.81, S D=1.28)$ and the value of "a little unusual" $(M=-1.00, S D=0.00)(Z=-1.26, p>0.1)$.

\section{Fair Consequentiality}

The rating of the event's impact, as appraised at the reception moment, $(M=0.41, S D=0.75)$ was significantly higher than the values of "moderate impact" $(M=0.00$, $S D=0.00) \quad(Z=-7.21, p<0.001)$, but significantly lower than "quite a bit of impact" $(M=1.00, S D=0.00)(Z=-7.21$ $p<0.001)$. The rating of current impact $(M=0.23, S D=0.80)$ was significantly higher than the value of "moderate impact" $(M=0.00, S D=0.00) \quad(Z=-4.15, p<0.001)$, but significantly lower than "quite a bit of impact" $(M=1.00$, $S D=0.00)(Z=-10.07 p<0.001)$.

\section{Fair Importance}

The rating of personal importance of the event $(M=0.70$, $S D=1.15$ ) was significantly higher than the values of "moderately important" $(M=0.00, S D=0.00) \quad(Z=-7.87$, $p<0.001)$, but significantly lower than "quite a bit important" $(M=1.00, S D=0.00)(Z=-4.14, p<0.001)$. The rating of importance of the event to family/friends $(M=0.56, S D=1.02)$ was significantly higher than the values of "moderately important" $(M=0.00, S D=0.00)(Z=-7.25, p<0.001)$, but significantly lower than "quite a bit important" $(M=1.00$, $S D=0.00)(Z=-6.16, p<0.001)$. No significant differences were observed between the rating of importance of the event to the country $(M=1.66, S D=0.68)$ and the value of "very important" $(M=2.00, S D=0.00)(Z=-0.56, p>0.1)$. The rating of importance of the event to the international community $(M=1.21, S D=0.97)$ was significantly higher than the values of "quite a bit important" $(M=1.00, S D=0.00)(Z=-3.20$, $p<0.001)$, but significantly lower than "very important" $(M=2.00, S D=0.00)(Z=-5.64, p<0.001)$.

\section{Significant Prior Knowledge}

No significant differences were observed between the rating of knowledge about the newspaper prior to the shooting $(M=1.87, S D=1.31)$ and "absolutely" $(M=2.00$, $S D=0.00)(Z=-0.43, p>0.1)$. The rating of reading the newspaper prior to the shooting $(M=-0.63, S D=1.11)$ was significantly higher than "a little" $(M=-1.00$, $S D=0.00)(Z=-9.11, p<0.001)$ but significantly lower than "moderately" $(M=0.00, S D=0.00)(Z=-11.91, p<0.001)$.

\section{Fair Sympathy}

No significant differences were observed between the rating of sympathy toward the newspaper $(M=0.85$, $S D=1.19)$ and "a little sympathetic" $(M=1.00, S D=0.00)$ $(Z=-1.57, p>0.1)$. The rating of agreement with the values of Charlie Hebdo $(M=0.33, S D=1.23)$ was significantly higher than "moderately" $(M=0.00, S D=0.00)(Z=-3.72$, $p<0.001)$, but significantly lower than "quite a bit" $(M=1.00, S D=0.00)(Z=-7.37, p<0.001)$.

\section{Flashbulb Memory Predicted by International Importance and Discussions with Others}

To identify the variables that best predicted flashbulb memory, a stepwise regression analysis was performed. The dependent variable was the sum of the correct answers to the ten flashbulb memory questions. Predictors were ratings on the five rehearsal items, the emotional valence item, the 14 emotional feeling items, the surprise item, the novelty item, the two consequentiality items, the four importance items, the two prior knowledge items, and the two opinion items. Analysis showed that flashbulb memory was predicted by ratings on the item "Is this event important to the international community?" (Adjusted $R^{2}=0.046, p<0.01$ ) and ratings on the item "Since its announcement, how many people have you talked to about the shooting?" (Adjusted $R^{2}=0.029, p<0.05$ ).

It is worth noting that, for all predictors, the Spearman correlation analysis showed significant correlations between flashbulb memory and rumination (Item 21) $(r=0.18, p<0.01)$, number of people with whom discussions were held (Item 23) $(r=0.20, p<0.01)$, emotional valence (Item 25) $(r=-0.17, p<0.01)$, and international importance (Item 47) $(r=-0.25, p<0.01)$.

\section{Discussion}

People often retain vivid memories of the circumstances of first learning about a significant public event. Our paper assesses whether such flashbulb recall was triggered by the attack on the satirical French newspaper "Charlie Hebdo". This was the case as our data showed substantial and vivid recall of the circumstances in which participants first learned of the attack. Our data also showed that the attack was associated with fair rehearsal, negative emotional valence, surprise, novelty, consequentiality, and importance. Furthermore, the flashbulb recall was predicted by the international importance of the attack and the number of people with whom discussions were held about the attack. 
Flashbulb memories have been observed for a wide range of significant public events, which occurred across countries and cultures. These studies highlighted the core element of flashbulb memories, that is, the significant recall of the context in which participants first learned about these events. This was also observed in our study as most participants succeeded in providing details about how they first became aware of the shooting. Most participants also gave details about where they were, with whom, what they were doing, what day of the week and what time it was when they learned about the shooting. They also described their feelings, reactions and thoughts when learning about the shooting.

Flashbulb recall involved significant vividness as our participants showed significant ratings of visual imagery, auditory imagery, physiological reaction, and mental time travel. These findings fit with the original concept of Brown and Kulik who defined flashbulb memories as vivid and long-lasting memories of attributes of the reception context of public news [1]. In a related vein, Kvavilashvili et al. also found fair vividness of remembering the circumstances in which British participants learned of the death of Princess Diana, even after a delay of 51 months [7]. Similarly, Berntsen and Thomsen found vivid recall in elderly Danes of the day of the German invasion of Denmark in World War II [22].

Vividness of flashbulb recall was especially observed for visual imagery since seeing the reception context was rated between "quite a bit" and "extremely" by our participants. Autobiographical memories are thought to be predominantly represented in the form of visual images [23] and visual imagery is considered a defining element of the sense of recollection and phenomenological experience of autobiographical recall [24].

Besides vividness, flashbulb memories were associated with fair rehearsal as our participants reported a high following of media reports, a tendency that was more than "many times a week" but less than "every day". This media following might increase processing of the event and its reception context, resulting in a high recall of the latter. Rehearsal may also have occurred when participants ruminated or talked about the event since they reported thinking and talking about the shooting more than "once a week" but less than "many times a week". Participants also reported talking about the shooting with more than "six to ten people" "in the following three days". In our view, rehearsal can improve flashbulb memories by reinforcing existing memory. It can also modify the content of these memories since, when talking about the events, people may gradually construct a story that addresses the communicative demands and the interpersonal situation rather than the accuracy of their recall [5].

Another feature of flashbulb memories, as observed in our study, was emotion as emotional rating was situated between "negative" and "very negative". Reflecting these outcomes, emotional involvement has been widely observed in research on flashbulb memories since these memories were found to imply greater emotional involvement than everyday life events [17]. Brown and Kulik also defined flashbulb memories as specific and vivid memories for emotionally arousing public events [1]. As for emotional feelings, participants reported being "quite a bit concerned", "quite a bit sad", "moderately furious", "quite a bit afraid", "moderately anxious", "quite a bit worried", "moderately panicked", "moderately powerless", "quite a bit disappointed", "quite a bit insecure" and "moderately frustrated". Their ratings were also higher than "quite a bit shocked" but lower than "very shocked", higher than "moderately confused" but lower than "quite a bit confused", higher than "moderately angry" but lower than "quite a bit angry". Hence, flashbulb memories seem to involve a wide variety of emotional states that range between moderate and high.

Flashbulb memories were also associated with some surprise as our participants reported being more than "quite a bit surprised" but less than "very surprised" by the event. By contrast, participants described the event as "a little unusual". Although one may expect more surprise and novelty when assessing flashbulb memories, novelty might not have been observed in our study as the newspaper had been threatened on several occasions. These threats were subject to extensive media coverage, which might have increased familiarity with them and decreased the level of novelty when the attacks occurred. This assumption can be supported by the substantial prior knowledge of our participants about the existence of the newspaper (Item 48) and potentially the threats. Nonetheless, although the newspaper had already been threatened, the intensity of the attack, the modus operandi and the timing (e.g. security measures implemented regarding the newspaper staff after the threat had been reduced) were unexpected, which may explain why the level of surprise remained high, despite a quite low level of novelty. Besides surprise and novelty, flashbulb memories in our study were associated with fair consequentiality as the rating of the event's impact was higher than "moderate impact" but lower than "quite a bit of impact". As for consequentiality, ratings of personal importance of the event and importance to family/friends were higher than "moderately important" but lower than "quite a bit important". The rating of importance to the country was "very important", while that to the international community was higher than "quite a bit important" but lower than "very important". Finally, participants reported being "a little sympathetic" toward the newspaper, and their agreement with its values was higher than "moderately" but lower than "quite a bit".

As highlighted in our study, flashbulb memories can be associated with several predictors, such as rehearsal, emotion, surprise, novelty, consequentiality, importance, prior knowledge and opinion. Among these factors, our regression analysis highlighted the international 
importance of the attack as a predictor of flashbulb recall. In the case of the Charlie Hebdo attack, international importance seems to play an important role as the attacks unleashed an international debate about freedom of expression and speech, not to mention international condemnation and solidarity with the victims. Besides the international importance, flashbulb recall in our study was predicted by the number of discussions that were held with others. Rehearsal may influence flashbulb memories by reinforcing existing memory; it may also modify the content of these memories since, when talking about the events, we may construct a story that addresses the communicative demands and the interpersonal situation. The involvement of rehearsal was further observed in our correlation analysis, showing a significant relationship between flashbulb recall and rumination. Correlation analysis also highlighted emotional valence. According to the Emotional-Integrative Model, emotional reaction ensures immediate adaptation to the unexpected public event, which influences encoding and processing of the reception context [5].

Regarding our method, one may argue that flashbulb memories should be evaluated in a test-retest perspective. In general, there are two different evaluations in the empirical literature on flashbulb memories. The first emphasizes the vividness of the recall [5] whereas the second emphasizes consistency between the initial test (usually shortly after encoding) and a retest [3]. We chose the first evaluation since we were interested in vividness and predictors of flashbulb memory rather than its consistency. However, one limitation of our method may lie in its web-based design. Although participants were asked not to search for answers (for event memory items) on the internet or elsewhere, we cannot rule out such a possibility. It is worth noting, however, that a substantial number of participants failed to determine the number of victims $(N=118)$ although this information is readily accessible on the internet.

To summarize, research suggests some culturally invariant features of autobiographical memory [12,23,25]. These cross-cultural characteristics are especially observed for flashbulb memories [19]. Our study contributes to these results by revealing flashbulb memories for the Charlie Hebdo attack in a French population. Our findings are also of particular interest since they link the formation of flashbulb memories to the international importance of the event.

\section{Acknowledgement}

The authors were supported by the National Center for Scientific Research (France).

\section{References}

1. Brown R, Kulik J. Flashbulb memories. Cognition 1977; 5: 73-99.

2. Bohn A, Berntsen D. Pleasantness bias in flashbulb memories: positive and negative flashbulb memories of the fall of the Berlin Wall among East and West Germans. Mem Cognit 2007; 35: 565-577.

3. Conway MA, Anderson SJ, Larsen SF, et al. The formation of flashbulb memories. Mem Cognit 1994; 22: 326-343.

4. Tekcan AI. Flashbulb memories for a negative and a positive event: News of Desert Storm and acceptance to college. Psychol Rep 2001; 88: 323-331.

5. Finkenauer C, Luminet O, Gisle L, et al. Flashbulb memories and the underlying mechanisms of their formation: Toward an emotional-integrative model. Mem Cognit 1998; 26: 516531.

6. Curci A, Luminet O, Finkenauer $\mathrm{C}$, et al. Flashbulb memories in social groups: a comparative test-retest study of the memory of French President Mitterrand's death in a French and a Belgian group. Memory 2001; 9: 81-101.

7. Kvavilashvili L, Mirani J, Schlagman S, et al. Comparing flashbulb memories of September 11 and the death of Princess Diana: Effects of time delays and nationality. Applied Cognitive Psychology 2003; 17: 1017-1031.

8. Conway ARA, Skitka LJ, Hemmerich JA, et al. Flashbulb memory for 11 September 2001. Applied Cognitive Psychology 2009; 23: 605-623.

9. Davidson PS, Cook SP, Glisky EL. Flashbulb memories for September 11th can be preserved in older adults. Aging Neuropsychology and Cognition 2006; 13: 196-206.

10. Greenberg DL. President Bush's false [flashbulb] memory of 9/11/01. Applied Cognitive Psychology 2004; 18: 363-370.

11. Hirst W, Phelps EA, Buckner RL, et al. Long-term memory for the terrorist attack of September 11: Flashbulb memories, event memories, and the factors that influence their retention. J Exp Psychol Gen 2009; 138: 161-176.

12. Hirst W, Phelps EA. Flashbulb memories. Curr Dir Psychol Sci 2016; 25: 36-41.

13. Pezdek K. Event memory and autobiographical memory for the events of September 11, 2001. Applied Cognitive Psychology 2003; 17: 1033-1045.

14. Talarico JM, Rubin DC. Confidence, not consistency, characterizes flashbulb memories. Psychol Sci 2003; 14: $455-461$

15. Tinti C, Schmidt S, Sotgiu I, et al. The role of importance/ consequentiality appraisal in flashbulb memory formation: The case of the death of Pope John Paul II. Applied Cognitive Psychology 2009; 23: 236-253.

16. Curci A, Lanciano T, Maddalena C, et al. Flashbulb memories of the Pope's resignation: Explicit and implicit measures across differing religious groups. Memory 2015; 23: $529-544$.

17. van Giezen AE, Arensman E, Spinhoven P, et al. Consistency of memory for emotionally arousing events: a review of prospective and experimental studies. Clin Psychol Rev 2005; 25: 935-953.

18. Luminet O, Curci A, Marsh EJ, et al. The cognitive, emotional and social impacts of the September 11 attacks: 
Group differences in memory for the reception context and the determinants of flashbulb memory. J Gen Psychol 2004; 131: 197-224.

19. Kulkofsky S, Wang Q, Conway MA, et al. Cultural variation in the correlates of flashbulb memories: An investigation in five countries. Memory 2011; 19: 233-240.

20. Shrout PE, Fleiss JL. Intraclass correlations: Uses in assessing rater reliability. Psychol Bull 1979; 86: 420-428.

21. Rubin DC, Schrauf RW, Greenberg DL. Belief and recollection of autobiographical memories. Mem Cognit 2003; 31: 887-901.

22. Berntsen D, Thomsen DK. Personal memories for remote historical events: Accuracy and clarity of flashbulb memories related to World War II. Journal of Experimental Psychology: General 2005; 134: 242-257.

23. Conway MA, Wang Q, Hanyu K, et al. A cross-cultural investigation of autobiographical memory: On the universality and cultural variation of the reminiscence bump. Journal of Cross-Cultural Psychology 2005; 36: 739-749.

24. Brewer WF. What is recollective memory? Remembering our past: Studies in autobiographical memory. Cambridge: Cambridge University Press 1996; 19-66.

25. Janssen SM, Chessa AG, Murre JM. The reminiscence bump in autobiographical memory: Effects of age, gender, education and culture. Memory 2005; 13: 658-668.

\section{Correspondence to:}

Mohamad El Haj,

Université de Lille 3,

Département de Psychologie,

Domaine du Pont de Bois,

B.P 60149. 59653, Villeneuve d'Ascq, France.

E-mail: mohamad.elhaj@univ-lille3.fr 